\title{
Neurosurgeons' opinions on the prenatal management of myelomeningocele
}

\author{
Pravesh S. Gadjradj, MD, ${ }^{1}$ Jochem K. H. Spoor, MD, ${ }^{2}$ Alex J. Eggink, MD, PhD, ${ }^{3}$ \\ René Wijnen, MD, PhD, ${ }^{4}$ Jena L. Miller, MD, ${ }^{5}$ Mara Rosner, MD, ${ }^{5}$ Mari L. Groves, MD, ${ }^{6}$ \\ Philip L. J. DeKoninck, MD, PhD, ${ }^{3}$ Biswadjiet S. Harhangi, MD, PhD, MSc, ${ }^{2}$ Ahmet Baschat, MD, ${ }^{5}$ \\ Marie-Lise van Veelen, MD, PhD, ${ }^{2}$ and Tjeerd H. R. de Jong, MD $^{2}$
}

1'Department of Neurosurgery, Leiden University Medical Center, Leiden; ${ }^{2}$ Department of Neurosurgery, Erasmus University Medical Center Rotterdam; ${ }^{3}$ Department of Obstetrics and Gynaecology, Division of Obstetrics and Fetal Medicine, Erasmus University Medical Center Rotterdam; ${ }^{\circ}$ Department of Pediatric Surgery, Erasmus University Medical Center Rotterdam, The Netherlands; and Departments of ${ }^{5}$ Gynecology \& Obstetrics and ${ }^{6}$ Neurosurgery, Johns Hopkins University, Baltimore, Maryland

OBJECTIVE Improvements in imaging and surgical technological innovations have led to the increasing implementation of fetal surgical techniques. Open fetal surgery has demonstrated more favorable clinical outcomes in children born with open myelomeningocele (MMC) than those following postnatal repair. However, primarily because of maternal risks but also because of fetal risks, fetal surgery for MMC remains controversial. Here, the authors evaluated the contemporary management of $\mathrm{MMC}$ in the hope of identifying barriers and facilitators for neurosurgeons in providing fetal surgery for MMC.

METHODS An online survey was emailed to members of the Congress of Neurological Surgeons (CNS) and the International Society for Pediatric Neurosurgery (ISPN) in March 2019. The survey focused on 1) characteristics of the respondents, 2) the practice of counseling on and managing prenatally diagnosed MMC, and 3) barriers, facilitators, and expectations of fetal surgery for MMC. Reminders were sent to improve the response rate.

RESULTS A total of 446 respondents filled out the survey, most (59.2\%) of whom specialized in pediatric neurosurgery. The respondents repaired an average of 9.6 MMC defects per year, regardless of technique. Regardless of the departments in which respondents were employed, $91.0 \%$ provided postnatal repair of MMC, $13.0 \%$ open fetal repair, and $4.9 \%$ fetoscopic repair. According to the surgeons, the most important objections to performing open fetal surgery were a lack of cases available to become proficient in the technique (33.8\%), the risk of maternal complications $(23.6 \%)$, and concern for fetal complications (15.2\%). The most important facilitators according to advocates of prenatal closure are a decreased rate of shunt dependency (37.8\%), a decreased rate of hindbrain herniation (27.0\%), and an improved rate of motor function (18.9\%). Of the respondents, only $16.9 \%$ agreed that open fetal surgery should be the standard of care.

CONCLUSIONS The survey results showed diversity in the management of patients with MMC. In addition, significant diversity remains regarding fetal surgery for MMC closure. Despite the apparent benefits of open fetal surgery in selected pregnancies, only a minority of centers and providers offer this technique. As a more technically demanding technique that requires multidisciplinary effort with less well-established long-term outcomes, fetoscopic surgery may face similar limited implementation, although the surgery may pose fewer maternal risks than open fetal surgery. Centralization of prenatal treatment to tertiary care referral centers, as well as the use of sophisticated training models, may help to augment the most commonly cited objection to the implementation of prenatal closure, which is the overall limited caseload.

https://thejns.org/doi/abs/10.3171/2019.7.FOCUS19362

KEYWORDS spina bifida; survey; fetal surgery; meningomyelocele

ABBREVIATIONS CNS = Congress of Neurological Surgeons; ISPN = International Society for Pediatric Neurosurgery; MMC = myelomeningocele; MOMS = Management of Myelomeningocele Study.

SUBMITTED May 31, 2019. ACCEPTED July 30, 2019.

INCLUDE WHEN CITING DOI: 10.3171/2019.7.FOCUS19362. 
$\mathrm{M}$ YELOMENINGOCELE (MMC), characterized by extrusion of the spinal cord together with the meningeal membranes, is the most severe and common form of spina bifida. ${ }^{11}$ Standard treatment is closure of the MMC defect within 48 hours of birth to minimize infectious and traumatic risk to the tissue. ${ }^{14,16}$ Since publication of the first case of surgical closure of an MMC defect in 1892, only limited progress has been made in surgical repair with the primary goals of creating a watertight closure over the open neural placode. ${ }^{6}$ Patients born with MMC can face lifelong disabilities such as neurological deficits below the level of the defect, hydrocephalus, hindbrain herniation, scoliosis, tethering of the spinal cord, urinary and fecal incontinence, and sexual dysfunction.

Early in vivo studies suggested that prenatal intervention could prevent secondary insults to the neural placode and the development of hindbrain herniation or hydrocephalus due to persistent intrauterine CSF leakage. Further surgical innovations and improvements in instrumentation refined this technique and improved mortality and morbidity rates. ${ }^{1,25}$ Initially, fetal surgery served as an option to treat potentially lethal conditions such as congenital diaphragmatic hernia, improving early mortality rates. ${ }^{19,28}$ With increasing knowledge and experience, the indications for fetal surgery have broadened toward treating nonlethal diseases such as MMC. ${ }^{1,8}$ At the end of the last century, early case studies of fetal MMC repair showed promising results and eventually led to a randomized controlled trial published in 2011.

In the Management of Myelomeningocele Study (MOMS), women diagnosed with a fetus having MMC were randomized to undergo either open fetal surgery before 26 weeks of gestation or conventional postnatal surgical repair. ${ }^{2}$ This trial was stopped prematurely given the efficacy of prenatal surgery. Results showed that only $40 \%$ of the prenatal surgery group needed placement of a shunt versus $82 \%$ in the postnatal surgery group at 1 year. In addition, children with MMC in the prenatal surgery group were less likely to have hindbrain herniation and were more likely to have a better level of motor functioning and to walk independently. However, these promising fetal outcomes came at the expense of maternal morbidity with higher rates of preterm delivery and a higher risk of maternal complications such as placental abruption and chorioamniotic membrane separation. Fetal surgery also carries risks for the fetus such as the need for transfusions and a lower birth weight. Furthermore, the MOMS had strict inclusion criteria, reflected by the fact that of the 1087 women who had undergone preliminary screening, only 183 underwent randomization.

Fetoscopic techniques were developed in the hopes of lowering maternal morbidity both in the current pregnancy and in future pregnancies. Developments and refinements have further improved fetoscopic techniques., ${ }^{9,22}$ Unlike open prenatal repair, fetoscopic surgery was less well received by the neurosurgical community because of the complexity of the procedure and less-established outcomes. ${ }^{12,13}$

With the rise of fetal surgery and the increasing evidence of its risks and benefits in treating selected pregnancies with $\mathrm{MMC}$, neurosurgeons may increasingly face ethical dilemmas, such as weighing maternal risks against potential fetal benefits. An expected paradigm shift in the treatment of MMC since publication of the MOMS results has led to an interest in knowing about the current management and application of fetal surgery by our colleagues. We aimed to identify the barriers and facilitators of fetal closure perceived by the neurosurgeons providing current techniques for MMC repair. Therefore, we conducted a survey on the management of MMC by neurosurgeons to evaluate the clinical practice worldwide.

\section{Methods}

Based on the literature, a first concept survey was developed. ${ }^{2-4,15,18,27}$ This survey was reviewed by two pediatric neurosurgeons experienced in treating MMC as well as a maternal-fetal medicine specialist before being finalized. The survey consists of 17 questions and can be divided into three sections: 1) characteristics of the respondents, such as subspecialization, tenure, and country of employment; 2) the practice of counseling on and managing MMC, such as the items discussed during counseling of parents, number of MMC defects closed yearly, and the availability of prenatal surgery to treat MMC; and 3) barriers, facilitators, and expectations of fetal surgery for MMC. The survey can be found in the Supplemental Material: Survey. The institutional review board waived the need for study approval as this research does not involve patients.

Members of the Congress of Neurological Surgeons (CNS) and the International Society for Pediatric Neurosurgery (ISPN) were approached by an email invitation containing a cover letter asking them to fill out a survey. The CNS was founded in 1951 and represents more than 9000 international members, who include residents, neurosurgeons, and medical students, among others. The ISPN consists of more than 350 pediatric neurosurgeons with the aim of improving the neurosurgical care of children. In March 2019 the survey was distributed by email, using SurveyMonkey. To increase the response rate, reminders were sent. By filling out a survey, respondents gave informed consent. Only responses from neurosurgeons and neurosurgery residents were included.

Data were analyzed using the IBM SPSS Statistics, version 21.0 for Windows (IBM Corp.). Descriptive statistics were used to present data in frequencies and percentages. Categorical data were analyzed using the chi-square test. A p value $<0.05$ was considered to be statistically significant.

\section{Results}

\section{Characteristics of the Respondents}

A total of 448 respondents filled out the survey. Two responses were not from neurosurgeons or neurosurgery residents and were therefore excluded. Eighty-four percent of the respondents were from the CNS, while the remaining $16 \%$ were from the ISPN. Respondents were employed in a total of 58 countries, with the US (56.3\%), Brazil (5.2\%), and India (4.9\%) having the most respondents (Fig. 1). Africa was the least represented (2.7\%; Table 1).

Respondents had a mean clinical experience of 21.6 \pm 12.9 years (mean \pm standard deviation), with residents 


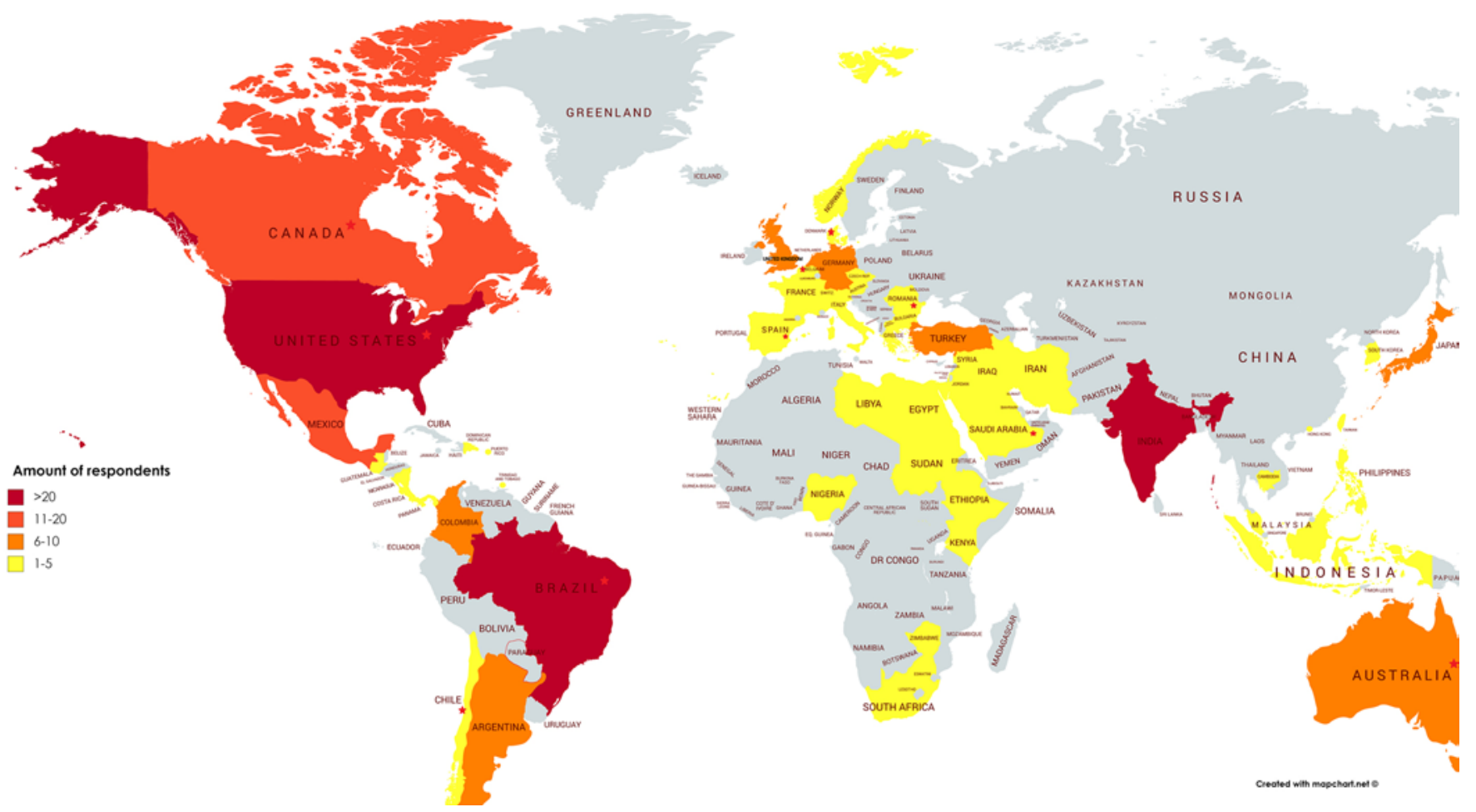

FIG. 1. A geographic overview of the working locations of the respondents. Countries marked with a star have one or more respondents providing prenatal closure techniques. Created with mapchart.net@. CC BY-SA 4.0 (https://creativecommons.org/licenses/ by-sa/4.0/).

having a mean clinical experience of 5.5 years (Table 1). Most of the respondents had pediatric neurosurgery as their subspecialization (59.2\%). Spine (29.6\%) and neurooncology (28.3\%) followed as the most frequent subspecializations.

Among the respondents, $81.0 \%$ treated patients with MMC. Neurosurgeons subspecialized in pediatric neurosurgery were more likely to treat patients with $\mathrm{MMC}$ $(\mathrm{p}<0.001)$. Among neurosurgeons not subspecialized in pediatric neurosurgery, $54.8 \%$ treated patients with MMC. Neurosurgeons performing closure of MMC defects operated on a mean of $9.6 \pm 17.9$ patients annually.

\section{Counseling and Management of MMC}

Three-quarters (74.5\%) of the neurosurgeons and 50\% of the residents deemed themselves sufficiently informed to counsel parents $(p=0.008)$, and $72.2 \%$ of the respondents actually counsel potential parents with children suspected to have MMC. Of those neurosurgeons who deemed themselves insufficiently informed to counsel, $37.2 \%$ still counsel potential parents. Table 2 gives an overview of several items discussed by respondents during the counseling of potential parents. All items differed statistically significantly between pediatric and nonpediatric neurosurgeons. Surgical closure of the MMC defect, the need for CSF shunting, and the expected level of motor function were always discussed by $83.1 \%, 75.3 \%$ and $69.4 \%$ of respondents, respectively. Termination of the pregnancy and the option of fetal surgery were never discussed by $35.6 \%$ and $23.7 \%$ of the neurosurgeons, respectively.
TABLE 1. Characteristics of the 446 respondents

\begin{tabular}{|c|c|}
\hline Variable & No. $(\%)$ \\
\hline \multicolumn{2}{|l|}{ Function } \\
\hline Neurosurgeon & $394(88.3 \%)$ \\
\hline Neurosurgeon in training & $52(11.7 \%)$ \\
\hline \multicolumn{2}{|l|}{ Specialty } \\
\hline Epilepsy & $39(8.7 \%)$ \\
\hline Functional & $28(6.3 \%)$ \\
\hline Peripheral nerve & $25(5.6 \%)$ \\
\hline Pediatrics & $264(59.2 \%)$ \\
\hline Neurooncology & $126(28.3 \%)$ \\
\hline Neurovascular & $83(18.6 \%)$ \\
\hline Neurotrauma & $93(20.9 \%)$ \\
\hline Spine & $132(29.6 \%)$ \\
\hline Other & $47(10.5 \%)$ \\
\hline Yrs of clinical experience & $21.6 \pm 12.9$ \\
\hline \multicolumn{2}{|l|}{ Continent of respondent } \\
\hline Africa & $12(2.7 \%)$ \\
\hline Asia \& Oceania & $67(15.0 \%)$ \\
\hline Europe & $45(10.1 \%)$ \\
\hline North America & $280(62.8 \%)$ \\
\hline South America & $42(9.4 \%)$ \\
\hline \multicolumn{2}{|l|}{ Department provides } \\
\hline Postnatal surgical closure of MMC & $406(91.0 \%)$ \\
\hline Open fetal surgery & $58(13.0 \%)$ \\
\hline Fetoscopic surgery & $22(4.9 \%)$ \\
\hline
\end{tabular}


TABLE 2. Items discussed during counseling by pediatric versus nonpediatric neurosurgeon respondents

\begin{tabular}{|c|c|c|c|}
\hline Item & Pediatric Neurosurgeons & Nonpediatric Neurosurgeons & $\mathrm{p}$ Value \\
\hline No. of respondents & 265 & 181 & \\
\hline Termination of pregnancy & & & $<0.001$ \\
\hline Always & $22.0 \%$ & $12.2 \%$ & \\
\hline Often & $8.2 \%$ & $3.8 \%$ & \\
\hline Sometimes & $17.1 \%$ & $13.7 \%$ & \\
\hline Rarely & $25.7 \%$ & $18.3 \%$ & \\
\hline Never & $26.9 \%$ & $51.9 \%$ & \\
\hline Repair of defect & & & $<0.001$ \\
\hline Always & $92.7 \%$ & $65.7 \%$ & \\
\hline Often & $4.1 \%$ & $10.4 \%$ & \\
\hline Sometimes & $1.2 \%$ & $4.5 \%$ & \\
\hline Rarely & $0.4 \%$ & $3.0 \%$ & \\
\hline Never & $1.6 \%$ & $16.4 \%$ & \\
\hline Need for CSF shunting & & & $<0.001$ \\
\hline Always & $85.4 \%$ & $57.0 \%$ & \\
\hline Often & $11.4 \%$ & $18.5 \%$ & \\
\hline Sometimes & $2.0 \%$ & $6.7 \%$ & \\
\hline Rarely & 0 & $2.2 \%$ & \\
\hline Never & $1.2 \%$ & $15.6 \%$ & \\
\hline Option of fetal surgery & & & $<0.001$ \\
\hline Always & $43.4 \%$ & $15.2 \%$ & \\
\hline Often & $13.1 \%$ & $10.6 \%$ & \\
\hline Sometimes & $14.8 \%$ & $17.4 \%$ & \\
\hline Rarely & $13.5 \%$ & $17.4 \%$ & \\
\hline Never & $15.2 \%$ & $39.4 \%$ & \\
\hline Hindbrain herniation & & & $<0.001$ \\
\hline Always & $66.9 \%$ & $36.6 \%$ & \\
\hline Often & $18.4 \%$ & $15.7 \%$ & \\
\hline Sometimes & $9.0 \%$ & $17.2 \%$ & \\
\hline Rarely & $3.7 \%$ & $11.9 \%$ & \\
\hline Never & $2.0 \%$ & $18.7 \%$ & \\
\hline Risk of spinal cord untethering & & & $<0.001$ \\
\hline Always & $68.2 \%$ & $44.8 \%$ & \\
\hline Often & $15.9 \%$ & $20.1 \%$ & \\
\hline Sometimes & $10.2 \%$ & $14.2 \%$ & \\
\hline Rarely & $4.1 \%$ & $3.7 \%$ & \\
\hline Never & $1.6 \%$ & $17.2 \%$ & \\
\hline Expected level of motor function & & & $<0.001$ \\
\hline Always & $76.8 \%$ & $55.6 \%$ & \\
\hline Often & $15.9 \%$ & $17.3 \%$ & \\
\hline Sometimes & $3.7 \%$ & $7.5 \%$ & \\
\hline Rarely & $0.8 \%$ & $2.3 \%$ & \\
\hline Never & $2.8 \%$ & $17.3 \%$ & \\
\hline Urological management & & & $<0.001$ \\
\hline Always & $80.1 \%$ & $48.9 \%$ & \\
\hline Often & $11.4 \%$ & $16.5 \%$ & \\
\hline Sometimes & $4.5 \%$ & $12.0 \%$ & \\
\hline Rarely & $1.2 \%$ & $3.0 \%$ & \\
\hline Never & $2.8 \%$ & $19.5 \%$ & \\
\hline
\end{tabular}




\section{» CONTINUED FROM PAGE 4}

TABLE 2. Items discussed during counseling by pediatric versus nonpediatric neurosurgeon respondents

\begin{tabular}{lccc}
\hline \multicolumn{1}{c}{ Item } & Pediatric Neurosurgeons & Nonpediatric Neurosurgeons & $p$ Value \\
\hline Orthopedic management & & & $<0.001$ \\
\hline Always & $58.4 \%$ & $31.6 \%$ & \\
\hline Often & $22.9 \%$ & $18.0 \%$ & \\
\hline Sometimes & $11.4 \%$ & $22.6 \%$ & \\
\hline Rarely & $4.5 \%$ & $6.8 \%$ & \\
\hline Never & $2.9 \%$ & $21.1 \%$ & \\
\hline
\end{tabular}

Ninety-one percent of the departments in which the neurosurgeons are employed provide conventional postnatal surgical closure of the MMC defect. Open fetal and fetoscopic procedures are provided by $13.0 \%$ and $4.9 \%$ of the centers, respectively. Four out of all centers provided fetal surgery but did not perform conventional postnatal surgery. Performing more surgical closures annually was not associated with providing fetal surgery $(p>0.05)$.

Table 3 gives an overview of the disciplines involved in the treatment of (unborn) patients with MMC. As regards clinical management by the respondents, neurosurgery $(78.0 \%)$, obstetrics $(77.4 \%)$, and pediatrics $(59.9 \%)$ were always involved in the care of MMC patients. Rehabilitation medicine, orthopedics, and neurology were never involved according to $27.5 \%, 26.6 \%$, and $23.4 \%$ of respondents, respectively. Pediatric neurosurgeons were less likely than nonpediatric neurosurgeons $(\mathrm{p}=0.002)$ to involve pediatrics.

\section{Barriers, Facilitators, and Expectations of Fetal Surgery for MMC}

When asked to rank the most important objections to providing open fetal surgery to treat MMC, $33.8 \%$ ranked "too few cases available to become proficient in the technique" as number one (Fig. 2). The risk of maternal complications and the risk of fetal complications were ranked second and third, respectively, by $23.6 \%$ and $15.2 \%$. Costs and ethical concerns were ranked last by $32.4 \%$ and $27.0 \%$, respectively.

The most important reason to provide open fetal surgery according to respondents was a decreased rate of shunt dependency (37.8\% of respondents; Fig. 3), followed by a decreased rate of hindbrain herniation $(27.0 \%$ of respondents) and an improved rate of motor function (18.9\% of respondents). Ranked last was the motivation to give parents a treatment option during gestation $(18.2 \%$ of respondents).

When comparing postnatal surgery with open fetal surgery and fetoscopic surgery, respondents expected the risk of maternal complications to be the highest for open fetal surgery (89.2\% of respondents), closely followed by fetoscopic surgery (79.9\% of respondents; Table 4). Conventional postnatal closure was expected to have the lowest risk (92.5\% of respondents). Open fetal surgery (70.6\% of respondents) and fetoscopic surgery (66.8\% of respondents) were expected to have the highest risks for perioper- ative fetal complications. No significant differences could be found in the expectations between countries providing fetal surgery and countries that do not. Furthermore, no significant differences could be identified between residents and neurosurgeons regarding barriers, facilitators, and expectations of fetal surgery (Fig. 3).

Table 5 gives an overview of respondent answers regarding the outcomes of open prenatal surgery. Among all respondents, $62.6 \%$ assumed that fetal surgery would lead to a higher risk of neonatal death, which contrasts with what the MOMS showed.

Table 6 gives an overview of respondent opinions regarding the position of fetal and fetoscopic surgery in the management of MMC. More than half of the respondents (54.4\%) disagreed or strongly disagreed that open fetal surgery should be the standard of care. Similarly, more than half of the respondents (58.1\%) disagreed or strongly disagreed that potentially damaging women as a result of fetal surgery is acceptable. Pediatric neurosurgeons were more likely than nonpediatric neurosurgeons to disagree on both of these items $(p<0.001$ and $p=0.003$, respectively). Reactions to the statement "denying potential improvement in the quality of life of MMC patients by not offering fetal surgery is acceptable" were more divided with almost a third (strongly) agreeing, a third being neutral, and almost a third (strongly) disagreeing. Slightly more than half (50.7\%) of the respondents strongly disagreed or disagreed with the statement that providing fetoscopic surgery without performing a randomized controlled trial is acceptable.

\section{Discussion}

This study gives an overview of the current management of MMC and opinions on fetal surgery by neurosurgeons worldwide. Open fetal surgery (13.0\%) and especially fetoscopic surgery (4.9\%) are provided by only a minority of the centers in which the respondents are employed. Despite the well-documented decreased rates of shunt dependency and hindbrain herniation and improved rate of motor function in strictly selected pregnancies, only $16.9 \%$ of respondents agreed that open fetal surgery should be the standard of care. The most important objections to the procedure are a limited caseload available to become proficient in the technique, the risk of maternal complications, and the risk of fetal complications. The bind in the trade-off between maternal health and the health and quality of life of patients with MMC is illus- 
TABLE 3. Disciplines involved in the management of MMC

\begin{tabular}{|c|c|c|c|}
\hline Discipline & Pediatric Neurosurgeons & Nonpediatric Neurosurgeons & $p$ Value \\
\hline Pediatrics & & & 0.002 \\
\hline Always & $55.6 \%$ & $71.3 \%$ & \\
\hline Often & $12.5 \%$ & $10.3 \%$ & \\
\hline Sometimes & $8.6 \%$ & $6.9 \%$ & \\
\hline Rarely & $16.8 \%$ & $1.1 \%$ & \\
\hline Never & $6.5 \%$ & $10.3 \%$ & \\
\hline Genetics & & & NS \\
\hline Always & $22.6 \%$ & $25.3 \%$ & \\
\hline Often & $23.9 \%$ & $26.6 \%$ & \\
\hline Sometimes & $27.4 \%$ & $22.8 \%$ & \\
\hline Rarely & $16.1 \%$ & $10.1 \%$ & \\
\hline Never & $10.0 \%$ & $15.2 \%$ & \\
\hline Neurosurgery & & & NS \\
\hline Always & $78.4 \%$ & $77.0 \%$ & \\
\hline Often & $15.2 \%$ & $8.0 \%$ & \\
\hline Sometimes & $4.0 \%$ & $6.9 \%$ & \\
\hline Rarely & $1.6 \%$ & $4.6 \%$ & \\
\hline Never & $0.8 \%$ & $3.4 \%$ & \\
\hline Orthopedics & & & NS \\
\hline Always & $21.7 \%$ & $16.7 \%$ & \\
\hline Often & $14.7 \%$ & $11.1 \%$ & \\
\hline Sometimes & $14.3 \%$ & $25.0 \%$ & \\
\hline Rarely & $23.5 \%$ & $18.1 \%$ & \\
\hline Never & $25.8 \%$ & $29.2 \%$ & \\
\hline Neurology & & & NS \\
\hline Always & $17.0 \%$ & $9.6 \%$ & \\
\hline Often & $18.8 \%$ & $17.8 \%$ & \\
\hline Sometimes & $20.6 \%$ & $35.6 \%$ & \\
\hline Rarely & $20.6 \%$ & $12.3 \%$ & \\
\hline Never & $22.9 \%$ & $24.7 \%$ & \\
\hline Obstetrics & & & NS \\
\hline Always & $78.5 \%$ & $75.0 \%$ & \\
\hline Often & $9.8 \%$ & $8.3 \%$ & \\
\hline Sometimes & $4.9 \%$ & $9.5 \%$ & \\
\hline Rarely & $4.5 \%$ & $3.6 \%$ & \\
\hline Never & $2.4 \%$ & $3.6 \%$ & \\
\hline Rehabilitation medicine & & & 0.001 \\
\hline Always & $33.5 \%$ & $31.6 \%$ & \\
\hline Often & $9.3 \%$ & $18.4 \%$ & \\
\hline Sometimes & $8.4 \%$ & $21.1 \%$ & \\
\hline Rarely & $19.5 \%$ & $6.6 \%$ & \\
\hline Never & $29.3 \%$ & $22.4 \%$ & \\
\hline Social work & & & NS \\
\hline Always & $38.7 \%$ & $46.2 \%$ & \\
\hline Often & $24.8 \%$ & $17.9 \%$ & \\
\hline Sometimes & $12.2 \%$ & $9.0 \%$ & \\
\hline Rarely & $12.2 \%$ & $10.3 \%$ & \\
\hline Never & $12.2 \%$ & $16.7 \%$ & \\
\hline
\end{tabular}


» CONTINUED FROM PAGE 6

TABLE 3. Disciplines involved in the management of MMC

\begin{tabular}{cccc}
\hline Discipline & Pediatric Neurosurgeons & Nonpediatric Neurosurgeons & p Value \\
\hline Urology & & & NS \\
Always & $33.2 \%$ & $32.9 \%$ & \\
\hline Often & $13.2 \%$ & $16.5 \%$ & \\
\hline Sometimes & $12.3 \%$ & $19.0 \%$ & \\
\hline Rarely & $20.5 \%$ & $22.9 \%$ & \\
\hline Never & $20.9 \%$ & $2 \%$ & \\
\hline
\end{tabular}

NS = not significant.

trated by the equally divided opinions regarding the statement that "denying potential improvement in the quality of life of MMC patients by not offering fetal surgery is acceptable."

\section{Comparison With Other Studies}

When the results of the MOMS were published in 2011, a paradigm shift was expected. ${ }^{2}$ However, such a shift was not reflected in our results: $23.7 \%$ of respondents never discuss the option of fetal surgery during counseling, and only $16.9 \%$ agree that open fetal surgery should be standard care. Moreover, only $13.0 \%$ of respondents offer open fetal surgery, while $4.9 \%$ offer fetoscopic surgery. An explanation for these low rates may be the generalizability of the MOMS, which included pregnancies carrying fetuses with MMC based on strict inclusion criteria. Results of fetal surgery for other pregnancies are less well-documented and warrant prospective studies. Another explanation may be the maternal comorbidity and the risk for future pregnancies. In the literature, a maternal complication rate of $6.2 \%$ for fetoscopic surgery and a rate of $20.9 \%$ for open fetal surgery have been reported. ${ }^{29}$ When taking into account only serious maternal complications such as those requiring ICU care or surgical intervention, risk rates of $1.7 \%$ and $4.5 \%$ have been reported for fetoscopic and open procedures, respectively.

Our results showed that $62.6 \%$ of the respondents assume that open fetal surgery carries a higher risk of neonatal death. Moreover, almost $40 \%$ wrongly assume a higher maternal mortality rate. These data may imply that a factor contributing to the nonoccurrence of the paradigm shift may be a lack of knowledge-on the one hand, a lack of knowledge because the outcomes reported in the literature may not be known among respondents, and on the other hand, because the results reported in the literature (e.g., MOMS) may not be generalizable to all pregnancies carrying fetuses with MMC.

Previous studies have shown that fetal surgery, especially fetoscopic surgery, is technically demanding and requires dedicated training. ${ }^{12,13,20}$ This may be reflected by the fact that only $4.9 \%$ of the departments surveyed provide fetoscopic surgery. A number of studies have been conduct-
Costs

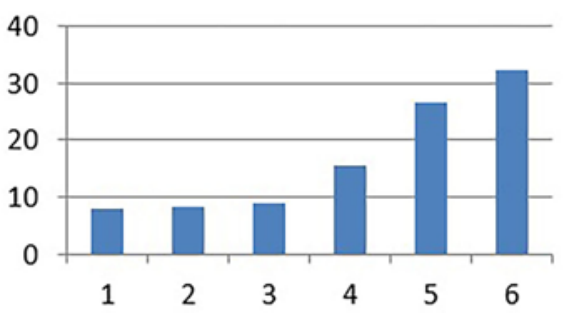

Too few cases available to become proficient

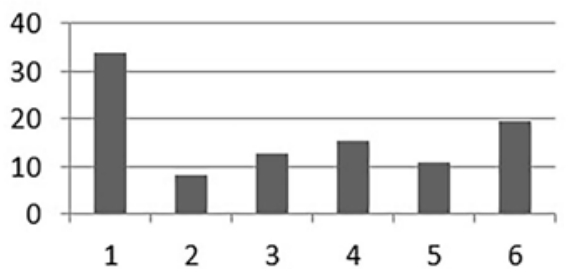

Ethical concerns

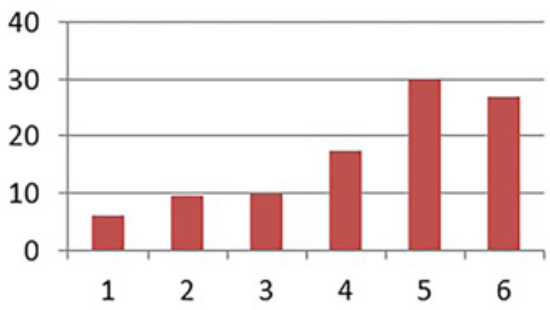

Maternal complications

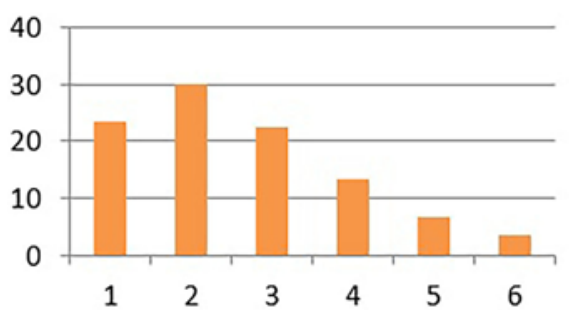

Fetal complications

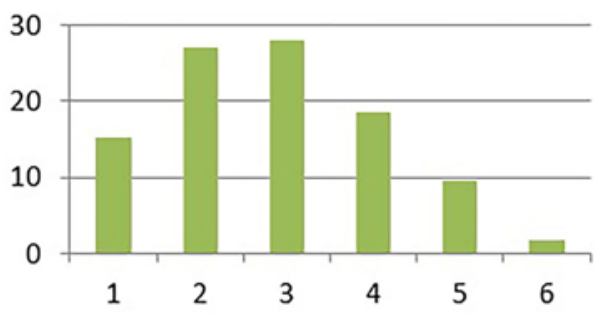

Evidence for benefit

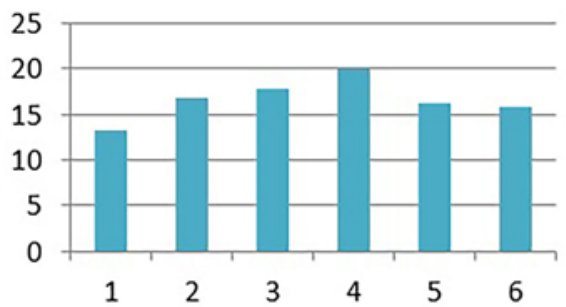

FIG. 2. The most important objections to providing open fetal surgery for the treatment of MMC. The y-axis represents the percentage of respondents. The $\mathrm{x}$-axis represents the rank chosen for each objection. 
Decreased rate of clinical hindbrain herniation

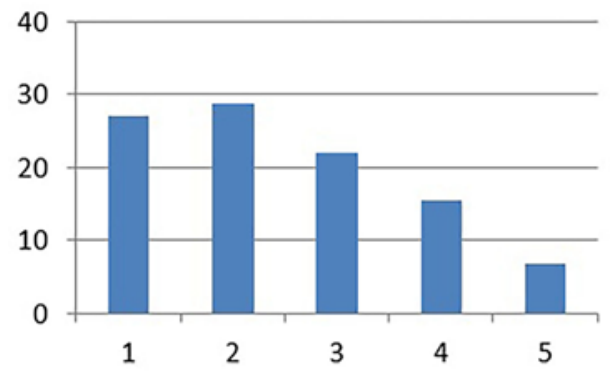

Improved rate of motor function

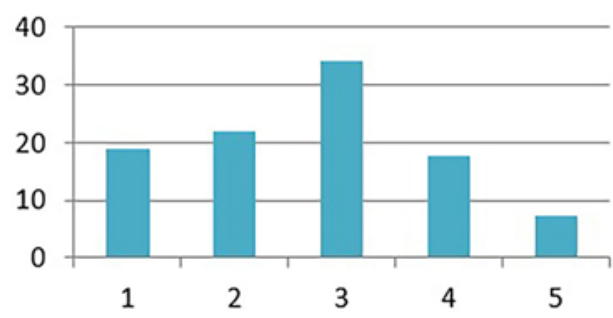

Decreased rate of shunt dependency

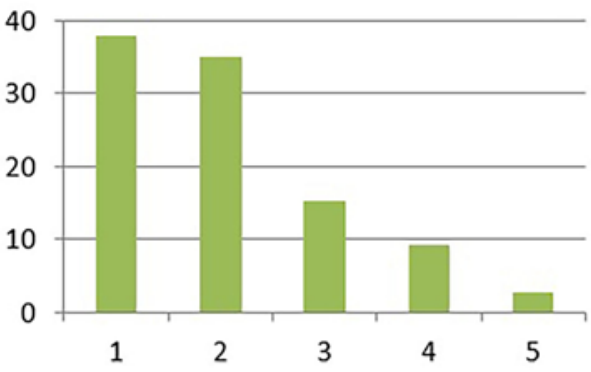

Offer parents a course of action

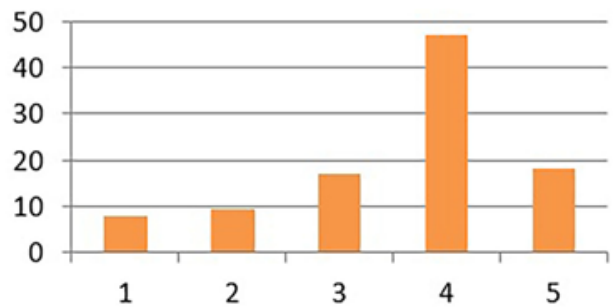

FIG. 3. The most important reasons to provide open fetal surgery for MMC. The $y$-axis represents the percentage of respondents. The $x$-axis represents the rank chosen for each expectation.

ed to assess the relationship between hospital and surgeon volume and surgical mortality and morbidity.,24 These studies have shown that a high surgeon volume results in superior outcomes for patients. Paradoxically, the majority of our respondents also agree that performing only one case of fetal surgery per month is acceptable, which mirrors the respondents' current practice of approximately 9.6 $\mathrm{MMC}$ repairs per year.

In light of the high case volume, the Maternal-Fetal Management Task Force released a position statement in which minimum criteria are recommended to ensure optimal maternal and fetal outcomes. ${ }^{10}$ In this statement, an initial experience of 5 cases is required, as is an adequate annual volume of cases to maintain proficiency. The exact number of cases meant by "adequate" is subject to debate,

TABLE 4. Expectations regarding the risks of maternal and fetal complications of three techniques to close MMCs

\begin{tabular}{crrr}
\hline & \multicolumn{3}{c}{ Level of Risk } \\
\cline { 2 - 4 } Complication \& Procedure & Most & Moderate & Least \\
\hline Maternal complication & & & \\
\hline Postnatal surgery & $2.7 \%$ & $4.8 \%$ & $92.5 \%$ \\
\hline Open fetal surgery & $89.2 \%$ & $8.8 \%$ & $2.0 \%$ \\
\hline Fetoscopic surgery & $79.9 \%$ & $13.6 \%$ & $9.5 \%$ \\
\hline Fetal complication & & & \\
\hline Postnatal surgery & $16.3 \%$ & $21.4 \%$ & $62.2 \%$ \\
\hline Open fetal surgery & $70.6 \%$ & $19.9 \%$ & $9.5 \%$ \\
\hline Fetoscopic surgery & $66.8 \%$ & $22.7 \%$ & $10.5 \%$ \\
\hline
\end{tabular}

however. A recent meta-analysis on the learning curves of fetal surgery estimated that competence for standard hysterotomy is reached after 35 cases and that competence for minimally invasive procedures is reached after 56 cases. $^{20}$

In this context, a smaller number of centers dedicated to fetal surgery, in which surgeons perform larger volumes of cases, is more desirable than a more disseminated offering of fetal surgery. A remedy toward achieving and maintaining proficiency may be adequate training models. ${ }^{26}$ Assisted nowadays by 3D-printed models, it is possible to create case-specific models to prepare for complex procedures such as fetoscopic surgery.

TABLE 5. Respondent knowledge about open prenatal surgery performed before 26 weeks of gestation

\begin{tabular}{|c|c|c|}
\hline \multirow[b]{2}{*}{ Statement } & \multicolumn{2}{|c|}{$\begin{array}{l}\text { Respondent } \\
\text { Answer }\end{array}$} \\
\hline & True & False \\
\hline $\begin{array}{l}\text { Fetal surgery leads to a higher risk of maternal } \\
\text { death }\end{array}$ & $39.4 \%$ & $60.6 \%$ \\
\hline $\begin{array}{l}\text { Fetal surgery leads to a higher risk of maternal } \\
\text { complications such as placental abruption }\end{array}$ & $90.6 \%$ & $9.4 \%$ \\
\hline $\begin{array}{l}\text { Fetal surgery leads to a higher risk of neonatal } \\
\text { death }\end{array}$ & $62.6 \%$ & $37.4 \%$ \\
\hline Fetal surgery halves the neonatal CSF shunt rate & $68.2 \%$ & $31.8 \%$ \\
\hline $\begin{array}{l}\text { Children who underwent prenatal surgery have a } \\
\text { lower level of mental \& motor function }\end{array}$ & $11.5 \%$ & $88.5 \%$ \\
\hline
\end{tabular}

Answers in boldface type indicate results of the MOMS. 
TABLE 6. Overview of respondent opinions regarding the place of fetal surgery in the management of MMC

\begin{tabular}{|c|c|c|c|}
\hline Statement & $\begin{array}{c}\text { Pediatric } \\
\text { Neurosurgeons }\end{array}$ & $\begin{array}{c}\text { Nonpediatric } \\
\text { Neurosurgeons }\end{array}$ & $\mathrm{p}$ Value \\
\hline Providing prenatal fetoscopic surgery w/o performing an RCT is acceptable & & & NS \\
\hline Strongly agree & $5.5 \%$ & $8.3 \%$ & \\
\hline Agree & $14.0 \%$ & $18.8 \%$ & \\
\hline Neutral & $25.5 \%$ & $31.3 \%$ & \\
\hline Disagree & $34.0 \%$ & $28.1 \%$ & \\
\hline Strongly disagree & $21.0 \%$ & $13.5 \%$ & \\
\hline Potentially damaging women due to fetal surgery is acceptable & & & 0.003 \\
\hline Strongly agree & $2.5 \%$ & $5.2 \%$ & \\
\hline Agree & $17.5 \%$ & $11.5 \%$ & \\
\hline Neutral & $17.5 \%$ & $34.4 \%$ & \\
\hline Disagree & $37.5 \%$ & $36.5 \%$ & \\
\hline Strongly disagree & $25.0 \%$ & $12.5 \%$ & \\
\hline Open fetal surgery should be standard care & & & $<0.001$ \\
\hline Strongly agree & $5.0 \%$ & $4.2 \%$ & \\
\hline Agree & $12.0 \%$ & $12.5 \%$ & \\
\hline Neutral & $21.5 \%$ & $43.8 \%$ & \\
\hline Disagree & $36.0 \%$ & $27.1 \%$ & \\
\hline Strongly disagree & $25.5 \%$ & $12.5 \%$ & \\
\hline A neurosurgeon performing only 1 fetal surgery case/mo is acceptable & & & 0.006 \\
\hline Strongly agree & $25.0 \%$ & $10.5 \%$ & \\
\hline Agree & $43.0 \%$ & $37.9 \%$ & \\
\hline Neutral & $13.5 \%$ & $25.3 \%$ & \\
\hline Disagree & $10.0 \%$ & $15.8 \%$ & \\
\hline Strongly disagree & $8.5 \%$ & $10.5 \%$ & \\
\hline $\begin{array}{l}\text { Denying potential improvement in } \mathrm{QOL} \text { of MMC patient by not offering fetal surgery } \\
\text { is acceptable }\end{array}$ & & & NS \\
\hline Strongly agree & $9.5 \%$ & $7.3 \%$ & \\
\hline Agree & $23.5 \%$ & $14.6 \%$ & \\
\hline Neutral & $31.0 \%$ & $41.7 \%$ & \\
\hline Disagree & $22.0 \%$ & $27.1 \%$ & \\
\hline Strongly disagree & $14.0 \%$ & $9.4 \%$ & \\
\hline
\end{tabular}

$\mathrm{QOL}$ = quality of life; RCT = randomized controlled trial.

Another debatable subject is the position of fetoscopic surgery. In a recent meta-analysis, outcomes of fetoscopic and open repair of MMC defects, published after MOMS, were analyzed and compared..$^{21} \mathrm{~A}$ total of 11 studies were included, 4 retrospective and 7 prospective, comprising 436 patients. Fetoscopic MMC repair (percutaneous or laparotomy access combined) was associated with a lower rate of uterine dehiscence; however, this came with a higher rate of dehiscence or CSF leakage of the MMC defect, requiring postnatal revision. There were no betweengroup differences regarding fetal and postnatal mortality, rate of shunt placement, reversal of hindbrain herniation, motor response, gestational age before birth, chorioamniotic membrane separation, or placental abruption. Expectations of our respondents were similar with $89.2 \%$ expecting open fetal surgery to have the highest risk for maternal complications. Authors of another meta-analysis concluded similarly, suggesting that before performing a randomized study, endoscopic techniques should be improved first. ${ }^{5}$

To date, no randomized controlled studies have compared the two techniques of fetoscopic and open postnatal repair. Only a minority of our respondents, $21.9 \%$ (strongly) believe it is acceptable to provide prenatal fetoscopic surgery without performing a randomized controlled trial. Fetoscopic surgery faces multiple barriers to implementation, as indicated by the reluctance of neurosurgeons to offer open fetal repair for MMC with only $13.0 \%$ of centers in our respondent pool offering the procedure.

\section{Study Strengths and Limitations}

Some limitations of this study must be acknowledged. First, the response rate could be a limitation. The survey was mailed to 7671 functional email addresses of CNS members. Three hundred seventy-four responses were from CNS members leading to an estimated response rate 
of $4.9 \%$. Of note, some of the email addresses may have belonged to medical students or other allied health professionals who may not have been eligible to fill out the survey. The importance of the response rate when judging the quality of cross-sectional research, however, is subject to debate. ${ }^{17,23}$ Given that 446 neurosurgeons with variable tenure and representing 58 countries responded to our survey, we expect a limited risk of nonresponse bias. However, we assume that MMC-dedicated centers, which also offer fetal surgery, may have been more inclined to respond.

Another limitation may be the unfamiliarity of the respondents with either the care of patients with MMC or prenatal surgery. However, $81.0 \%$ stated that they treat patients with MMC and $91.0 \%$ worked at a department where either postnatal or prenatal surgery is provided.

\section{Conclusions}

The survey results show the diversity in the management of patients with MMC. In addition, significant diversity remains regarding fetal surgery for MMC closure. Despite the apparent benefits of open fetal surgery in selected pregnancies, only a minority of centers and providers offer this technique. As a more technically demanding technique that requires multidisciplinary effort with lesswell-established long-term outcomes, fetoscopic surgery may face similar limited implementation, although the surgery may pose fewer maternal risks than open fetal surgery. Centralization of prenatal treatment to tertiary care referral centers, as well as the use of sophisticated training models, may help to augment the most commonly cited objection to the implementation of prenatal closure, which is the overall limited caseload.

\section{Acknowledgments}

We would like to thank all respondents for sharing their opinions and clinical management with us. These include Frank Van Calenbergh, Vaverka Miroslav, Salvatore Chibbaro, Micyn Micunovic, Erwin Cornips, Bernt Due-Tønnessen, Bruno Lourenço Costa, Horia Ples, José Hinojosa, John Goodden, Tony Magana, Seraj S. Ajaj, Olufemi Idowu, Abubakr Darrag Salim Ahmed, Patrick McDonald, Jose Javier Cuellar Hernandez, Edgar Fernando Acosta Gómez, Rolando Jimenez-Guerra, Marco Enrique Munoz Lopez, Robin Bowman, Jay Wellons, P. Langham Gleason, Amos Stoll, Erik C. Brown, David Cech, Richard P. Moser, J. Paul Muizelaar, Curtis J. Rozzelle, Jesse Winer, Jodi L. Smith, William E. Whitehead, Christopher Bonfield, Arnett Klugh III, Alejandro Carlo Cardona Gonzales, Jose Aloysio da Costa Val Filho, Reynaldo Andre Brandt, Hamilton Matushita, Ricardo Santos de Oliveira, Eduardo Jucá, Artur Henrique Galvao Bruno Da Cunha, Alexandre Maués da Costa, J. Francisco Salomão, Enrico Ghizoni, Felipe Otayza, William Cortés Lozano, R. Andrew Danks, Juliet Clayton, Rakshith Shetty, Santosh Mohan Rao Kanangi, Prakash Singh, Sharath Kumar Maila, Vijay Parihar, Sri Maliawan, Julius July, Nobuhito Mopota, Ryo Ando, Azmi Alias, Jafri Malin Abdullah, Wisam Issawi, and Mustafa Altennari.

\section{References}

1. Adzick NS, Sutton LN, Crombleholme TM, Flake AW: Successful fetal surgery for spina bifida. Lancet 352:1675-1676, 1998

2. Adzick NS, Thom EA, Spong CY, Brock JW III, Burrows PK, Johnson MP, et al: A randomized trial of prenatal ver- sus postnatal repair of myelomeningocele. N Engl J Med 364:993-1004, 2011

3. Antiel RM, Collura CA, Flake AW, Johnson MP, Rintoul NE, Lantos JD, et al: Physician views regarding the benefits and burdens of prenatal surgery for myelomeningocele. J Perinatol 37:994-998, 2017

4. Antiel RM, Flake AW, Collura CA, Johnson MP, Rintoul NE, Lantos JD, et al: Weighing the social and ethical considerations of maternal-fetal surgery. Pediatrics 140: e20170608, 2017

5. Araujo Júnior E, Eggink AJ, van den Dobbelsteen J, Martins WP, Oepkes D: Procedure-related complications of open vs endoscopic fetal surgery for treatment of spina bifida in an era of intrauterine myelomeningocele repair: systematic review and meta-analysis. Ultrasound Obstet Gynecol 48:151-160, 2016

6. Bayer C: Zur technik der operation der spina bifida und encephalocele. Prag med Wchnschr 17:317, 332, 345, 1892

7. Birkmeyer JD, Stukel TA, Siewers AE, Goodney PP, Wennberg DE, Lucas FL: Surgeon volume and operative mortality in the United States. N Engl J Med 349:2117-2127, 2003

8. Bruner JP, Tulipan N, Paschall RL, Boehm FH, Walsh WF, Silva SR, et al: Fetal surgery for myelomeningocele and the incidence of shunt-dependent hydrocephalus. JAMA 282:1819-1825, 1999

9. Bruner JP, Tulipan NB, Richards WO, Walsh WF, Boehm $\mathrm{FH}$, Vrabcak EK: In utero repair of myelomeningocele: a comparison of endoscopy and hysterotomy. Fetal Diagn Ther 15:83-88, 2000

10. Cohen AR, Couto J, Cummings JJ, Johnson A, Joseph G, Kaufman BA, et al: Position statement on fetal myelomeningocele repair. Am J Obstet Gynecol 210:107-111, 2014

11. Copp AJ, Adzick NS, Chitty LS, Fletcher JM, Holmbeck GN, Shaw GM: Spina bifida. Nat Rev Dis Primers 1:15007, 2015

12. Degenhardt J, Schürg R, Winarno A, Oehmke F, Khaleeva A, Kawecki A, et al: Percutaneous minimal-access fetoscopic surgery for spina bifida aperta. Part II: maternal management and outcome. Ultrasound Obstet Gynecol 44:525-531, 2014

13. Farmer DL, von Koch CS, Peacock WJ, Danielpour M, Gupta $\mathrm{N}$, Lee $\mathrm{H}$, et al: In utero repair of myelomeningocele: experimental pathophysiology, initial clinical experience, and outcomes. Arch Surg 138:872-878, 2003

14. Fichter MA, Dornseifer U, Henke J, Schneider KT, Kovacs L, Biemer E, et al: Fetal spina bifida repair-current trends and prospects of intrauterine neurosurgery. Fetal Diagn Ther 23:271-286, 2008

15. Fruhman G, Miller C, Amon E, Raible D, Bradshaw R, Martin K: Obstetricians' views on the ethics of cardiac surgery for newborns with common aneuploidies. Prenat Diagn 38:303-309, 2018

16. Gross RH, Cox A, Tatyrek R, Pollay M, Barnes WA: Early management and decision making for the treatment of myelomeningocele. Pediatrics 72:450-458, 1983

17. Groves RM, Peytcheva E: The impact of nonresponse rates on nonresponse bias - a meta-analysis. Public Opin Q 72:167-189, 2008

18. Heuser CC, Eller AG, Byrne JL: Survey of physicians' approach to severe fetal anomalies. J Med Ethics 38:391-395, 2012

19. Jani JC, Nicolaides KH, Gratacós E, Valencia CM, Doné E, Martinez JM, et al: Severe diaphragmatic hernia treated by fetal endoscopic tracheal occlusion. Ultrasound Obstet Gynecol 34:304-310, 2009

20. Joyeux L, De Bie F, Danzer E, Russo FM, Javaux A, Peralta CFA, et al: Learning curves of open and endoscopic fetal spina bifida closure: a systematic review and meta-analysis. Ultrasound Obstet Gynecol [epub ahead of print], 2019

21. Kabagambe SK, Jensen GW, Chen YJ, Vanover MA, Farmer DL: Fetal surgery for myelomeningocele: a systematic review 
and meta-analysis of outcomes in fetoscopic versus open repair. Fetal Diagn Ther 43:161-174, 2018

22. Kohl T: Percutaneous minimally invasive fetoscopic surgery for spina bifida aperta. Part I: surgical technique and perioperative outcome. Ultrasound Obstet Gynecol 44:515-524, 2014

23. Livingston EH, Wislar JS: Minimum response rates for survey research. Arch Surg 147:110, 2012

24. Lopez Ramos C, Brandel MG, Rennert RC, Hirshman BR, Wali AR, Steinberg JA, et al: The potential impact of "Take the Volume Pledge" on outcomes after carotid artery stenting. Neurosurgery [epub ahead of print], 2019

25. Meuli M, Meuli-Simmen C, Hutchins GM, Yingling CD, Hoffman KM, Harrison MR, et al: In utero surgery rescues neurological function at birth in sheep with spina bifida. Nat Med 1:342-347, 1995

26. Miller JL, Ahn ES, Garcia JR, Miller GT, Satin AJ, Baschat AA: Ultrasound-based three-dimensional printed medical model for multispecialty team surgical rehearsal prior to fetoscopic myelomeningocele repair. Ultrasound Obstet Gynecol 51:836-837, 2018

27. Moldenhauer JS, Adzick NS: Fetal surgery for myelomeningocele: after the Management of Myelomeningocele Study (MOMS). Semin Fetal Neonatal Med 22:360-366, 2017

28. Ruano R, Yoshisaki CT, da Silva MM, Ceccon ME, Grasi MS, Tannuri U, et al: A randomized controlled trial of fetal endoscopic tracheal occlusion versus postnatal management of severe isolated congenital diaphragmatic hernia. Ultrasound Obstet Gynecol 39:20-27, 2012

29. Sacco A, Van der Veeken L, Bagshaw E, Ferguson C, Van Mieghem T, David AL, et al: Maternal complications following open and fetoscopic fetal surgery: a systematic review and meta-analysis. Prenat Diagn 39:251-268, 2019

\section{Disclosures}

The authors report no conflict of interest concerning the materials or methods used in this study or the findings specified in this paper.

\section{Author Contributions}

Conception and design: Gadjradj, Spoor, Eggink. Acquisition of data: Gadjradj, de Jong. Analysis and interpretation of data: Gadjradj, Spoor, DeKoninck. Drafting the article: Gadjradj. Critically revising the article: all authors. Reviewed submitted version of manuscript: all authors. Approved the final version of the manuscript on behalf of all authors: Gadjradj. Statistical analysis: Gadjradj. Administrative/technical/material support: Gadjradj. Study supervision: Gadjradj, Wijnen, Miller, Rosner, Groves, Harhangi, Baschat, van Veelen, de Jong.

\section{Supplemental Information}

Online-Only Content

Supplemental material is available online.

Supplemental Material: Survey. https://thejns.org/doi/suppl/ 10.3171/2019.7.FOCUS19362.

\section{Correspondence}

Pravesh S. Gadjradj: Leiden University Medical Center, Leiden, The Netherlands.p.gadjradj@erasmusmc.nl. 